\title{
Implementasi Teknologi Informasi untuk Peramalan Dinamika Bisnis (Studi Pada Bisnis Valas)
}

\author{
$\mathbf{1}_{\text {Khofifah Amalia }}$ \\ Universitas Islam Negeri Sunan Ampel Surabaya \\ amaliakhofifah37@gmail.com \\ 2 Amalia Salsabila Ariyanto \\ Universitas Islam Negeri Sunan Ampel Surabaya \\ Amaliasalsa28@gmail.com
}

\begin{abstract}
This study aims to determine the implementation of information technology in foreign exchange. By using quantitative and qualitative research methods as well as associative. research that comes from the presence of data and utilizes existing theories as an explanation. With the development of technology, every company tries to always provide the best service to its customers in the business field. In the business sector, technology plays an important role, especially in banking. It cannot be separated from one that we may rarely hear but which plays an important role in the business world, namely the existence of foreign exchange. Foreign currency or commonly referred to as foreign exchange is the currency that is used as a legal tender in the country. Foreign currency will have a value if that foreign currency can be exchanged for another foreign currency without restrictions. Foreign exchange transactions can occur in the foreign exchange market.
\end{abstract}

\section{Keywords: Implementation, Information Technology, Foreign Exchange}

\begin{abstract}
ABSTRAK
Penelitian ini bertujuan untuk mengetahui implementasi teknologi informasi pada valas. Dengan menggunakan metode penelitian kuantitatif dan kualitatif serta bersifat asosiatif. penelitian yang bersumber dari adanya data dan memanfaatkan teori yang sudah ada sebagai penjelas. Dengan semakin berkembangnya teknologi, setiap perusahaan berusaha selalu memberikan pelayanan terbaik kepada pelanggannya dalam bidang bisnis. Dalam bidang bisnis, teknologi memegang peranan penting terutama dalam perbankan. Tidak lepas dari salah satu yang mungkin jarang kita dengar namun sangat berperan penting dalam dunia bisnis yaitu adanya valas. Valuta asing atau biasa disebut valas merupakan mata uang yang digunakan sebagai alat pembayaran yang sah di negara. Valas akan mempunyai suatu nilai apabila valas tersebut dapat ditukarkan dengan valas lainnya tanpa pembatasan Transaksi valas dapat terjadi di pasar valas.
\end{abstract}

Kata Kunci : Implementasi, Teknologi Informasi, Valuta Asing 


\section{PENDAHULUAN}

Dengan adanya teknologi informasi (TI) tidak dapat dipungkiri bahwa perkembangannya telah masuk ke banyak bidang, mulai dari segi penjualan, bisnis bahkan perbankan. Terlebih, dalam mencapai keselarasan proses yang terjadi antara teknologi dan bisnis. Mudahnya, bisnis adalah kegiatan menjual barang atau jasa kepada konsumen dengan tujuan untuk mendapatkan laba atau keuntungan. Bisnis umumnya dijalankan sebuah perusahaan dalam bentuk komunitas usaha tertentu, seperti misalnya perusahaan persorangan, persekutuan ataupun perseroan.

Semakin berkembangnya teknologi, setiap perusahaan berusaha selalu memberikan pelayanan terbaik kepada pelanggannya dalam bidang bisnis. Dalam bidang bisnis, teknologi memegang peranan penting terutama dalam perbankan. Tidak lepas dari salah satu yang mungkin jarang kita dengar namun sangat berperan penting dalam dunia bisnis yaitu adanya Valuta Asing. Menurut Ekawati (2017) Valuta asing atau biasa disebut Valas merupakan mata uang yang digunakan sebagai alat pembayaran yang sah di negara.

Valas akan mempunyai suatu nilai apabila valas tersebut dapat ditukarkan dengan valas lainnya tanpa pembatasan Transaksi valas dapat terjadi di pasar valas. Pasar valas adalah pasar tempat pertukaran berbagai macam mata uang yang berbeda, tentunya nilai tukar valas berdasarkan kurs yang ada di negara tersebut. Adapun kurs merupakan harga mata uang yang akan di tukar dengan mata uang lainnya yang berlaku di suatu negara. Valas berperan penting dalam ekspor dan impor. Banyaknya transaksi akan berpengaruh pada besarnya potensi rugi selisih kurs sehingga dibutuhkan pengelolaan valuta asing. (Chairiel Oktaviar, 2017)

Tak hanya sebagai alat tukar menukar, valas juga memiliki banyak fungsi. Diantara lain dengan adanya pasar valas, maka pemerintah juga dapat mengendalikan kurs. Apakah mata uang negara tersebut melemah atau menguat. Juga, dengan adanya valuta asing perdangan internasional semakin mudah. Dengan perkembangan teknologi siapa saja bisa melakukan transaksi perdagangan antar negara. Dengan tidak adanya valas maka perdagangan internasional dapat terganggu, bahkan kemungkinan tidak bisa melakukan transaksi. (Anzaludin Perbangsa, Reyner, Aloysius Nugroho, Joshua J, Junne, 2019,)

Sekarang ini nilai tukar rupiah hingga mencapai level diatas 12.000 rupiah per dolar AS hal itu dapat dikatakan bahwa rupiah semakin melemah. (Akhsanul Haq dan Andir Muniroh, 2015) Banyak analisis ekonomi dan pemerintah yang berkata bahwa, rupiah memang salah satu mata uang terlemah di dunia, yang nilainya mudah turun hanya karena perubahan kondisi ekonomi baik di luar maupun di dalam negeri. Pada pertumbuhan perekonomian nasional dan global ditunjukan rupiah dalam perlambatan dan diperkirakan akan turun nilai mata uangnya terhadap mata uang lainnya.

Oleh karena itu idealnya seluruh kewajiban yang segera harus dibayar dan hak yang segera harus diterima dalam berbagai jenis valuta operasional yang digunakan harus dilindungi terhadap perubahan kurs yang tidak dapat diperkirakan secara akurat. Untuk menjamin jumlah yang harus dibayar dan hak penerimaan dalam valas asing, persetujuan perusahaan yang dapat dilakukan pembelian atau penjualan valas dengan menggunakan kontrak forward, kontrak masa depan dan opsi kontrak (call dan put).

\section{LANDASAN TEORI}

Menurut Sawidji dkk (2007 : 72), terdapat dua jenis analisis utama dalam perdagangan valas yang dilakukan pedagang atau trader untuk menentukan waktu membeli dan menjual dalam pasar mata uang, yaitu analisis fundamental dan teknikal. Analisis fundamental yaitu analisis terhadap fundamental suatu negara pemilik mata uang. Sementara analisis teknikal, analisis ini bergantung tren harga ke depan berdasar perkembangan harga yang terjadi pada 
waktu lalu. Dalam melakukannya, pedagang dan investor cenderung menggunakan salah satu atau kombinasi dari kedua analisis ini.

Ada berbagai macam analisis teknikal yang dapat digunakan dalam menganalisis perdagangan valuta asing. Untuk melakukan analisis teknikal diperlukan analisis yang disebut indikator. Ada lebih dari 50 jenis indikator dalam analisis teknikal. Beberapa indikator yang terkenal diantaranya adalah Moving Average (MA), Bollinger Band (BB), Relative Strength Index (RSI), Stochastic, dan Moving Average Convergence Divergence (MACD), dan lainlain. Indikator yang dipilih dan populer adalah MA, yang merupakan pergerakan rata-rata harga yang ditentukan pada periode tertentu. Bollinger Bands untuk mengukur tingkat volatilitas (kestabilan pergerakan harga).

Stochastic adalah indikator lain yang dapat membaca kapan saja tren akan berakhir. RSI hampir sama dengan Stochastic untuk menunjukkan kondisi yang muncul setelah melakukan aksi beli atau jual selama beberapa waktu yaitu overbought dan oversold. Sementara MACD merupakan indikator momentum yang menunjukkan hubungan antara dua Moving Average dari pergerakan harga selama jangka waktu tertentu. Kelebihan dari MACD yaitu keliru memberikan sinyal palsu karena grafik pergerakan yang lebih halus. Tujuan dibuatnya artikel ini adalah untuk mencoba menganalisis valuta asing dengan menggunakan MACD.

\section{METODE PENELITIAN}

Jenis penelitian ini menggunakan metode penelitian kuantitatif dan kualitatif serta bersifat asosiatif. Penelitian dengan metode kuantitatif bertujuan untuk menguji hipotesis yang telah ditetapkan. Sedangkan metode penelitian kualitatif yaitu penelitian yang bersumber dari adanya data dan memanfaatkan teori yang sudah ada sebagai penjelas. Sifat asosiatif yang dimaksud disini adalah untuk mengetahui hubungan antara dua variabel atau lebih. Disini untuk lebih jelasnya digunakan juga metode simulasi yang didasarkan pada alternative metode lindung nilai kurs valuta asing yang ada di Indonesia.

\section{PEMBAHASAN}

\section{Teknologi Informasi dan Bisnis}

Teknologi informasi adalah suatu studi perancangan, implementasi, pengembangan, dukungan atau manajemen sistem informasi berbasis komputer terutama pada aplikasi hardware (perangkat keras) dan software (perangkat lunak komputer). Sedangkan bisnis adalah usaha menjual barang atau jasa yang dilakukan oleh perorangan, sekelompok orang atau organisasi kepada konsumen (masyarakat) dengan tujuan utamanya adalah memperoleh keuntungan/laba (profit).

Bisnis dan teknologi informasi merupakan dua hal yang berkaitan. Terlebih di era saat ini teknologi memiliki peran yang besar bagi aktivitas manusia. Sehingga pengaruh teknologi informasi tidak dapat diremehkan, karena proses globalisasi yang berjalan begitu cepat yang memberikan pengaruhi pada cara berpikir maupun berperilaku. Peran pentingnya teknologi informasi ini juga memberikan pengaruh pada dunia bisnis. Pada dunia bisnis teknologi membantu banyak terutama terkait sistem informasi yang terintegrasi dengan baik, yang mana sistem informasi yang terintegrasi dibangun atau dirancang untuk mengatasi sekaligus membantu para pelaku bisnis dalam menjalankan bisnis ke arah yang lebih baik. Selain itu, pekerjaan atau aktivitas yang berhubungan bisnis akan lebih mudah dengan memanfaatkan sistem kerja yang efektif dan efisien. 


\section{Valuta Asing}

Valuta asing atau biasa disebut valas adalah mata uang asing yang digunakan sebagai alat pembayaran. Valas dalam bahasa Inggris dikenal dengan nama foreign exchange (Forex). Valas dapat dijadikan suatu bentuk investasi dan diperdagangkan secara umum. Adapun wujud dari valuta asing berupa mata uang asing, Tidak setiap mata uang asing dapat dipakai langsung untuk melakukan pembayaran internasional, tetapi harus ditukarkan terlebih dahulu dengan mata uang yang berlaku secara internasional. Mata uang yang sering dipakai sebagai alat transaksi disebut hard currency, yaitu mata uang yang nilainya kuat dan relatif stabil serta mengalami apresiasi terhadap mata uang lain.

Contoh dari hard currency adalah mata uang dari negara maju seperti dollar amerika, euro Eropa, dan yen Jepang. Sedangkan mata uang yang nilainya lemah dan relatif kurang stabil nilainya serta jarang digunakan disebut soft currency. Mata uang yang termasuk soft currency ini sering mengalami depresiasi dan penurunan nilai terhadap mata uang lainnya. Mata uang yang termasuk soft currency adalah mata uang dari negara-negara berkembang seperti rupiah Indonesia, bath Thailand, dong Myanmar, dan peso Fillipina.

Bagi pelaku usaha di negara dengan mata uang soft currency yang bergerak dibidang impor, saat akan melakukan impor diharuskan untuk menukar mata uang asal dengan mata uang hard currency di pasar valuta asing atau Money Changer dengan nilai kurs yang belaku. Valuta asing memiliki sistem kurs. Menurut undang-undang no. 24 tahun 1999, bank Indonesia diberikan kewenangan untuk menentukan sistem nilai kurs yang berlaku. Dalam penentuan sistem kurs valuta asing ada tiga cara yang digunakan yaitu Kurs tetap (Fixed Exchange Rate), Kurs Mengambang (Floating Exchange Rate), dan Kurs Distabilkan (Managed Floating Rate).

\section{Pelaku Pasar Valuta Asing}

Pasar valuta asing dapat dibedakan menjadi dua kategori, yaitu pasar klien dan pasar antar bank. Dalam pasar klien, bank bertransaksi langsung dengan nasabahnya. Nasabah bank adalah pemerintah, Bank Sentral, Individu, Pialang pasar, Spekualan, dan lembaga keuangan yang tidak memiliki akses ke pasar antar bak. Setiap orang bisa menjadi pelaku pasar valas.

1. Perorangan atau perusahaan

Sebuah perusahan atau seseorang dapat menggunakan valuta asing (valas) dalam melaksanakan perdagangan dalam pasar valuta asing (valas). Contohnya : seperti eksportir maupun importir, investor internasional, dan lain sebagainya.

2. Bank sentral

Dalam hal ini bank sentral memiliki peran untuk menstabilkan kurs mata uang dari negara yang dikenal atau bersangkutan, dan bank sentral memiliki fungsi serta peran sebagai pengawas dan pengendalian dalam melakukan transaksi jual beli valuta asing (valas).

3. Pemerintah

Pemerintah memiliki tujuan untuk membayar hutang luar negeri dalam valuta asing (valas) tersebut.

4. Arbitrator dan spekulen

Dalam aerbitrator dan spekulen ini umunya ialah orang-orang yang mengeksploitasi perbedaan pada kurs mata uang asing.

5. Dealer (Market Maker)

Dealer memiliki fungsi sebagai pihak yang dapat membuat pasar menjadi bergairah dalam pasar uang.

6. Pialang 
Pialang merupakan orang yang memiliki fungsi sebagai perantara untuk mempertemukan antara permintaan dan penawaran terhadap mata uang tertentu.

\section{Jenis-Jenis Valuta Asing}

Valas atau valuta asing dibedakan menjadi dua kelompok, dan berikut ini adalah penjelasan dari keduanya:

1. Valuta asing fisik

Dalam valuta fisik ini berkaitan erat mengenai uang asing atau uang dari negara lain yang berbentuk uang kartal, baik berupa uang kertas bank, uang kertas negara maupun uang logam.

2. Valuta asing non fisik

Berbeda dengan valuta asing fisik, dalam valuta asing non fisik ini uang yang beredar didalamnya adalah yang berbnetuk uang giral atau surat-surat berharga. Misalnya seperti cek, wesel, internasional money, travelers, dan cheque.

\section{Implementasi Teknologi Informasi}

Pemrograman merupakan kegiatan menuliskan kode program yang akan di eksekusi oleh komputer. Kode program yang akan ditulis oleh programmer ini harus sesuai dengan dokumentasi yang disediakan oleh analisis sistemnya, hasil dari desain sistem secara rinci. Sesuai dengan rancangan fisik sebagai dokumentasi aplikasi, maka aplikasi yang dibuat haruslah sesuai dengan dokumentasi yang telah dibuat. Dalam penerapan kodekode program yang membangun aplikasi ini juga harus diuji agar terhindar dari kesalahan program secara menyeluruh.

\section{a. Uji White Box}

Uji white box menggunakan struktur control rancangan untuk memperoleh test case. Didasarkan pengamatan yang teliti tahap detail prosedur dan jalur logika yang melewati perangkat lunak diuji dengan memberikan test case yang menguji serangkaian kondisi atau loop tertentu.

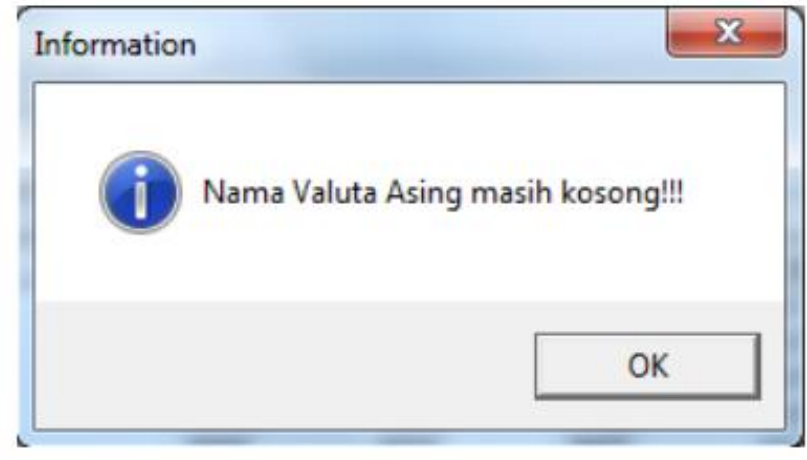

Gambar 4.9 Uji White Box

b. Uji Black Box

Uji black box yaitu pengujian spesifikasi suatu fungsi atau modul apakah berjalan sesuai dengan yang diharapkan atau tidak. Pengujian ini dilakukan pada seluruh modul yang ada. 


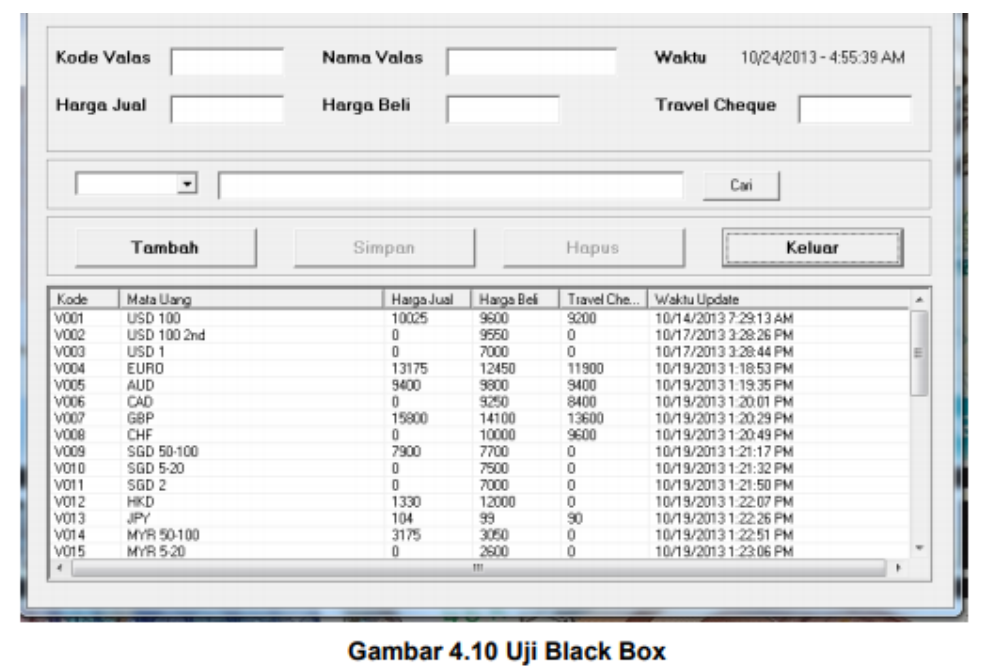

\section{KESIMPULAN}

Pengaruh teknologi informasi saat ini tidak dapat diremehkan, karena proses globalisasi yang mempengaruhi cara berpikir maupun berperilaku di dalam persaingan di dunia bisnis dan organisasi. Setiap organisasi bisnis pun bertumbuh kembang secara pesat dikarenakan teknologi paling baru sangat berpengaruh kemajuan organisasi. Teknologi informasi tanpa bisnis, teknologi itu tidak dapat dijalankan secara maksimal yang menghambat perkembangan jaman sedangkan bisnis tanpa teknologi informasi, bisnis tersebut akan mati karena persaingan yang begitu ketat. Oleh karena itu pengaruh teknologi informasi ini terhadap aktifitas dan perilaku organisasi terutama bisnis sangat diperlukan . Dan hal ini tentunya dimaksudkan untuk mendukung penerapan sistem informasi agar dapat berjalan dengan baik dan selaras dengan apa yang dibutuhkan oleh manajemen organisasi bisnis tersebut.

\section{Daftar Pustaka}

Bakampung, Trivena Fristy (2013). Analisis Fluktasi Valuta Asing RP/USD Pengaruhnya Terhadap Volume Ekspor di Sulawesi Utara, Jurnal EMBA, Volume 1. No.3.

Ekawati, Rika( 2017) Perencanaan Infrastruktur Teknologi Informasi Pada Bank Dengan Framework TOGAF, Jurnal Sistem Informasi Bisnis, Volume 7.

Haq, Akhsanul, Andir Muniroh (2015). Analisis Pengelolaan Valuta Asing Terhadap Profitabilitas PT Garuda Indonesia, JIAFE (Jurnal Ilmiah Akuntansi Fakultas Ekonomi), Volume 1, No. 2.

Hutabarat, Lawrence Hasiolan, Sujoko (2010). Analisa Manajemen Resiko dan Strategi Investasi Pada Forex Online Trading dan Pengaruhnya Terhadap Value Added Investor di PT. Monex Investindo Futures, DIE( Jurnal Ilmu Ekonomi dan Manajemen), Volume 6, No.2.

Oktaviar, Chairiel(2017). Analisa Pengaruh Pengelolaan Valuta Asing Terhadap Potensi Pendapatan Selisih Kurs, Jurnal Ilmiah Manajemen Bisnis, Volume 3, No. 01.

Perbangsa, Anzaludin, Reyner, Aloysius Nugroho, Joshua J, Junne (2019). Pengembangan system Informasi Jasa Penukaran Valas, Jurnal Teknologi Informasi, Volume 5. 
Wuri, Josephine (2018). Fluktasi Kurs Valuta Asing Di Beberapa Negara Asia Tenggara, EXERO: (Journal of Research in Business and Economics), Volume 1, No. 01.

https://zahiraccounting.com/id/blog/bisnis-dan-teknologi-informasi-apa-hubungannya/ diakses 30 April 2020

https://kamus.tokopedia.com/v/valuta-asing/ diakses pada 2 Mei 2020

https://www.simulasikredit.com/apa-itu-valas-definisi-valuta-asing/ diakses pada 2 Mei 2020

https://japandiadam.wordpress.com/2012/09/29/apakah-yang-dimaksud-dengan-bisnis/ diakses pada 3 Mei 2020 